\title{
LEIBNIZ, MOLYNEUX E AS CAUSAS FINAIS: UMA OCASIÃO DE DISPUTA PERDIDA
}

\author{
Emanuele Tredanaro
}

UFLA

\begin{abstract}
RESUMO: Neste trabalho, nos propomos percorrer algumas etapas do debate sobre a relevância das causas finais nas investigações físicas, que levou Leibniz a confrontar sua filosofia, de modo particular, com o cartesianismo e, mais em geral, com uma concepção estritamente mecanicista da natureza. Serão seguidos aqueles indícios que se encontram na obra de Leibniz, ao procurar pelas referências a Molyneux, um dos primeiros a receber e divulgar a perspectiva leibniziana, e, além disso, um dos poucos interlocutores com os quais se instaurou um diálogo de tons cordiais. Tentaremos mostrar que, todavia, tal troca não polêmica é fruto de um desentendimento de fundo entre os dois intelectuais.
\end{abstract}

PALAVRAS-CHAVE: Leibniz; Molyneux; causalidade; finalismo; mecanicismo.

ABSTRACT: In this paper, we propose to move through some steps of the debate about the relevance of final causes in physical investigations, which led Leibniz to compare his philosophy, in particular, with Cartesianism and, more generally, with a strictly mechanistic view of nature. We will follow the signs of this debate in work of Leibniz, signs that could be found in search of references to Molyneux, one of the first to receive and publicize Leibniz's perspective, and also one of the few interlocutors with whom a cordial dialogue was established. We will try to show that, however, such no polemic exchange is the result of a fundamental misunderstanding between the two intellectuals.

KEYWORDS: Leibniz; Molyneux; causality; finalism; mechanism.

É sabido que, em sua tentativa de refutação passo a passo do Essay lockeano, Leibniz foi um dos primeiros ${ }^{1}$ a dedicar atenção à questão proposta a Locke pelo amigo e colega Molyneux desde $1688^{2}$, e publicada pelo filósofo

1 Entre os outros, Edward Synge e Francis Quayle em sua correspondência (cf. SYNGE, 1695) e, naturalmente, Berkeley, o primeiro a manifestar-se publicamente sobre 0 assunto (cf. BERKELEY, 1709, seção CXXXII ss.).

${ }^{2}$ A questão é apresentada por Molyneux a Locke em duas versões diferentes. A primeira, em uma carta (cf. MOLYNEUX, 1688) que, embora não tenha recebido resposta, serviu para solicitar a futura 


\section{Dossiê Leibniz, Dissertatio - Volume Suplementar 03 UFPel [2016]}

inglês na segunda edição de seu tratado (cf. LOCKE, 1694, II.ix.8). Talvez, seja menos notório que, embora a referência ao problema de Molyneux ocorra apenas uma vez na obra de Leibniz - mais exatamente nos NE (cf. GP V 123.07126.18) -, ela não representa propriamente a única referência a Molyneux, o qual recebe reiterada menção nos escritos filosóficos e em algumas cartas do intelectual alemão. Todos esses outros casos referem-se, à primeira vista, a simples ocasiões aproveitadas por Leibniz para agradecer a Molyneux, por este ter julgado digno de menção, em sua Dioptrica nova, publicada em $1692^{3}$, o ensaio leibniziano, Unicum opticae, catoptricae e dioptricae principium, de 1682.

Além da indicação presente no início da primeira parte da Dioptrica nova, na qual Molyneux promete retomar com mais vagar a hipótese leibniziana sobre a explicação do desvio dos raios de luz refratados através de corpos de diversas densidades (cf. MOLYNEUX, 1692, p. 2), é só após aproximadamente duzentas páginas, no primeiro capítulo da segunda parte da obra, que Molyneux efetivamente expõe a demonstração de Leibniz. Na verdade, a essa altura de seu tratado, respectivamente nos parágrafos 2 e 3, Molyneux insere uma tradução de dois trechos das cinco páginas que compõem o ensaio de Leibniz de 1682. Enquanto a tradução da primeira passagem respeita ao pé da letra o original em

correspondência entre os dois intelectuais, a partir de 1692. A segunda versão é proposta em outra carta (cf. MOLYNEUX, 1693) que, finalmente, consegue suscitar o interesse de Locke sobre 0 assunto.

${ }^{3}$ Os elementos pré-textuais presentes na própria Dioptrica Nova, permitem retrodatar a obra: 0 imprimatur do vice-presidente da Royal Society, John Hoskyns, na primeira folha do livro, apresenta a data de 4 de junho de 1690; a dedicatória de Molyneux à Royal Society, assim como a advertência ao leitor, são ambas datadas de 7 de abril de 1690. Em todo caso, o que importa ressaltar é que Molyneux já há anos ia confrontando-se com questões de óticas, em particular, através do confronto com a Dioptrique de Descartes (cf., por exemplo, LIEVERS, 1992, p. 402-405). 
latim (cf. MOLYNEUX, 1692, p. 192.08-194.24, e LEIBNIZ, 1682, p. 185.01186.21), a segunda passagem do texto de Leibniz é reproposta por Molyneux através de uma tradução livre, aparentemente fiel e não prejudicial ao original (cf. MOLYNEUX, 1692, p. 195.04-17, e LEIBNIZ, 1682, p. 186.24-34). Nesta última passagem da Dioptrica nova, Molyneux assim traduz as palavras de Leibniz:

(3.) One thing more there is remarkable in the Learned Leibnutius Discourse, which I cannot here pass over, and that is, A pious Reflection which he makes on this occasion, concerning Final Causes. For 'tis manifest, that the Ray proceeding from $\mathrm{C}$, does not consult with it self, how it may with the greatest ease arrive at the Point $\mathrm{E}$, or D, or G; neither is it carried by it self to those Points. But the Great Creator of all things, has so made Light, that this most beautiful, orderly, and admirable Event should result from its very Nature. Wherefore they are in a great Error, who reject Final Causes in Natural Philosophy, which, besides affording us occasion of admiring and adoring the Divine Wisdom, do often discover to us a curious Principle of finding out the Properties of those things whose inward Nature is not so clearly known by us, as that we can explain the immediate efficient Causes and Instruments, which the Almighty Mover imploys in producing those Effects, and obtaining those Ends (MOLYNEUX, 1692, p.195.1-17, itálico no original).

É significativo que Molyneux introduza a tradução desta parte do ensaio de Leibniz, qualificando o assunto em questão, as causas finais, de um lado, como "mais algo digno de destaque" que não pode ser desconsiderado, e, de outro, como "reflexão piedosa". Se levarmos a sério tais palavras, notaremos certa tensão, pois as causas finais, de um lado, são apontadas como elemento em certa medida relevante no interior de explicações científicas, como a que aqui está sendo proposta; de outro, são reconduzidas à mera esfera religiosa. Ao tentarmos uma interpretação, nos parecem sinalizadoras as palavras enfatizadas 


\section{Dossiê Leibniz, Dissertatio - Volume Suplementar 03 UFPel [2016]}

em itálico por Molyneux, e, em geral, a tradução por ele oferecida. Através da estratégia gráfica, Molyneux, além de evidenciar qual o tema aqui tratado, as causas finais (assim como Leibniz faz em seu próprio texto), ressalta também os termos-chave que mostram a polaridade problemática da questão (sendo que no texto de Leibniz são outros os termos salientados). O leitor é convidado a focar sua atenção: no reflexo da grandiosidade do criador na ordem e beleza dos eventos e dos entes naturais criados, das quais a luz é um exemplo paradigmático; no auxílio que a sabedoria divina oferece ao conhecimento humano limitado; no paralelismo entre a relação causas eficientes-efeitos e aquela meios-fins, ou seja, entre curso da natureza e ação divina.

Molyneux parece assumir uma posição muito cautelosa que nos permite mais algumas observações relativas à sua tradução do texto de Leibniz, cuja versão original diz:

Reduximus ergo omnes radiorum leges experientia comprobatas ad puram Geometriam, \& calculum, unico adhibito principio, sumto a causa finali, si rem recte consideres; neque enim radius e $\mathrm{C}$ egrediens consultat, quomodo ad punctum E, vel D, vel, G pervenire quam facillime possit, neque per se ad ipsa refertur; sed Conditor rerum ita creavit lucem, ut ex ejus natura pulcherrimus ille eventus nasceretur. Itaque errant valde, ne quid gravius dicam, qui causas finales cum Cartesio in Physica rejiciunt; cum tamen praeter admirationem divinae sapientiae, pulcherrimum nobis principium praebeant inveniendi earum quoque rerum proprietates, quarum interior natura nondum tam clare nobis cognita est, ut causis efficientibus proximis uti, machinasque, quas conditor ad effectus illos producendos, finesque suos obtinendos adhibuit, explicare valeamus (LEIBNIZ, 1682, p. 186.22-34, itálico no original $)^{4}$.

${ }^{4} \mathrm{~A}$ demonstração toda, desde o início, se baseia no pressuposto que um "[punctum] E sumi debet tale, ut a sit omnium facillima" (LEIBNIZ, 1682, p. 185.27), pressuposto por sua vez fundamentado na "hypothesis primaria" que "lumen a puncto radiante ad punctum illustrandum pervenit via omnium facillima" (idem, $\mathrm{p}$. 
De imediato, não podemos deixar de notar que Molyneux, simplesmente, escolhe não traduzir as linhas iniciais dessa passagem, inseridas por Leibniz exatamente entre os dois consistentes trechos dos quais a Dioptrica nova apresenta a tradução. Molyneux cuida de omitir justamente as palavras com as quais Leibniz, após ter apresentado a demonstração matemático-geométrica do desvio dos raios de luz refratados através de corpos de diversas densidades, introduz, pela primeira vez explicitamente em seu ensaio, as causas finais. Parece-nos, todavia, imprescindível considerarmos a centralidade que, em seu raciocínio, Leibniz reserva à causalidade final, pois é, de certo modo, pelo seu viés que é possível identificar o único princípio matemático-geométrico válido para a explicação mecanicista de ótica, catóptrica e dióptrica. O mesmo resultado obtido pela demonstração matemático-geométrica, a saber, que os senos complementares de raios de luz refratados estão em uma proporção inversa com a resistência do meio de refração, pode ser inferido seja por um cálculo trigonométrico seja mediante observações que visem explicar as causas como meios voltados a determinados fins. Ademais, a causalidade final traz à tona o olhar retrospectivo próprio do processo de descoberta científica, o qual adquire pleno sentido por indagar as causas físico-mecânicas a partir da pretensão de explicá-las em conexão sistemática com efeitos que não são por elas produzidos aleatoriamente, pois, ao contrário, inerem às causas como fins 


\section{Dossiê Leibniz, Dissertatio - Volume Suplementar 03 UFPel [2016]}

necessários, conforme a própria natureza das coisas ${ }^{5}$. Se na demonstração de Leibniz há legitimidade - e Molyneux concorda explicitamente com isso (cf. MOLYNEUX, 1692, p. 194.25-32) -, então, a pressuposição de uma causalidade de tipo final em nada lesa o princípio a partir do qual é comprovado, de um ponto de vista matemático-geométrico, o mecanismo da refração. Ao contrário, o confirma, contribuindo para a maior compreensibilidade de sua explicação, ao oferecer uma explicação que vá além da particularidade do fenômeno ${ }^{6}$. Não se trata, portanto, de um mero addendum, de mais um aspecto interessante a ser relevado, ou apenas de um sinal de devoção religiosa; ao contrário, está aqui sendo exposto por Leibniz o coração do problema: não se dá uma explicação verdadeiramente clara da natureza através de leis que apontem para suas

\footnotetext{
${ }^{5}$ Ainda em 1679, Leibniz escreve: "Rerum Genera sequuntur Causae. Omnis causa confert aliquid ad Effectum. Hoc tamen non sufficit, nam potest aliquid conferre ad effectum, qui tamen non sequitur; quod scilicet alia requisita desint, aut quaedam impediant, itaque requiritur, ut Effectus etiam sequatur. Proinde causa est conferens cum successu. Conferens est quod non quidem absolute ad rem requiritur, requiritur tamen ad eam secundum certum producendi modum. Causa igitur est requisitum rei secundum eum producendi modum quo reapse producta est. Requisitum est aliquid re natura prius, quo non posito ipsa existere non potest. At inquies ergo finis non est causa. Et sane fateor finem non esse causam, non enim existit, sed ejus conceptum esse causam et quidem inter efficientes, nempe impellentem" (AA VI.4: 308.1623). É de notar a complexa articulação do raciocínio leibniziano, voltado a mostrar a objetividade peculiar da causalidade final: em primeiro lugar afirma-se que a causa é requisito da coisa, isto é, determina a própria existência da coisa, conforme seu modo de produzir-se; secundariamente, que, propriamente falando, o fim não existe, pois efeito ainda a vir, então, não é causa e não participa da determinação da existência da coisa; todavia, é o conceito de fim, como efeito necessariamente pressuposto, a ser propriamente causa, ou seja, causa eficiente, pois é a pressuposição do efeito que determina a causa como seu correlato necessário (se não se pressupuser efeito, não se pode falar de causa), isto é, o requisito pelo qual a coisa existe. Nesse sentido, o fim age sobre a coisa determinando causalmente sua existência.

${ }^{6}$ Poucos anos depois, no Discours de Métaphysique, Leibniz assim formulará a questão: "Et il paroist de plus en plus quoyque tous les phenomenes particuliers de la nature se puissent expliquer mathematiquement ou mechaniquement par ceux qui les entendent, que neantmoins les principes generaux de la nature corporelle, et de la mechanique même sont plustost metaphysiques que Geometriques, et appartiennent plustost à quelques formes ou natures indivisibles comme causes des apparences qu'à la masse corporelle ou étendue" (AA VI.4: 1559.13-18).
} 
determinações mecânicas, se não considerarmos também suas determinações finalísticas. Seria até possível descrevermos os eventos naturais - por exemplo, as dinâmicas específicas do fenômeno da luz -, mas não seria o suficiente para alcançarmos uma explicação de tais eventos, por assim dizer, satisfatória, pois sistemática.

Desta leitura, decorrem as observações seguintes. Embora seja retomada indiretamente (cf. idem), Molyneux não apresenta a referência a Descartes nesta altura de sua tradução. Essa referência corresponde a uma das poucas palavras que se encontram em itálico na passagem original de Leibniz, junto com a expressão "principium inveniendi". Também mediante os recursos gráficos, parece evidente que, para Leibniz, o cerne da questão, constituído pela impossibilidade de eliminar as causas finais das explicações da física, reenvia à querela com interlocutores específicos, a saber, Descartes e os cartesianos da escola. Conforme a perspectiva de Leibniz, estes erram ao defender uma visão da ciência da natureza exclusivamente mecanicista, visão compartilhada em linhas gerais pelo empirista Molyneux. Na verdade, em jogo parece estar mais que um simples engano metodológico, como Leibniz deixa entender, notando en passant que a acusação contra seus adversários poderia ser mais grave. Não reconhecer uma relação necessária entre as causas dos fenômenos naturais e os fins em vista dos quais elas produzem determinados efeitos conforme a própria natureza escolhida por Deus para as coisas, consequentemente, não reconhecer validade à perspectiva finalística na investigação científica, reenvia, pois, à tese 


\section{Dossiê Leibniz, Dissertatio - Volume Suplementar 03 UFPel [2016]}

cartesiana de Deus criar, em seu infinito poder e arbítrio, as leis físicas segundo fins insondáveis para o intelecto humano finito. Conforme a perspectiva cartesiana, é na exclusão do acesso aos fins estabelecidos por Deus para a natureza que encontra respaldo a independência do método de investigação e explicação mecanicista adotado pela física ${ }^{7}$, no que diz respeito ao finalista adotado pela metafísica. Seria despida de sentido a pretensão de raciocinarmos acerca dos fenômenos físicos segundo causas finais, pois simplesmente estas, mesmo que reais, dadas a perfeição e bondade divina, estão ao alcance só de Deus. Todavia, Leibniz não pode não alertar do perigo spinozista implícito na posição de Descartes ${ }^{8}$ : deslegitimar as causas finais em nome da inescrutabilidade da vontade de Deus levaria enfim a reduzi-las a meras ficções dos homens, como sustenta Spinoza ${ }^{9}$, na medida em que Deus opere de maneira verdadeiramente incompreensível para nós. Para Leibniz, é como se a

\footnotetext{
${ }^{7}$ Cf., por exemplo, Descartes, 1641, AT IX: 44.24-28: "[...] tout ce genre de causes, qu'on a coutume de tirer de la fin, n'est d'aucun usage dans les choses physiques, ou naturelles; car il ne me semble pas que je puisse sans témérité rechercher et entreprendre de découvrir les fins impénétrables de Dieu". Cf. também Descartes, 1644, AT IX: 37.13-27 e 104.01-15.

${ }^{8}$ Desde logo, Leibniz vê em Spinoza um epígono de Descartes Por exemplo, já em 1678/1680 (a datação é incerta), ou seja, pouco depois da publicação da Ethica, Leibniz escreve: "La secte des nouveaux Stoiciens croit [...] qu'il [Dieu] est cause de la matiere même si vous voulés, mais que c'est une necessité aveugle qui le determine à agir: c'est pourquoy il sera dans le monde ce que le ressort ou le poids est dans l'horloge. Qu'il y a une necessité machinale dans les choses, que c'est bien par le pouvoir, mais non pas par un choix raisonnable de cette Divinité que les choses agissent, puisqu'à proprement parler Dieu n'a ny entendement ny volonté, qui sont des attributs des hommes. Que toutes les choses possibles arrivent l'une après l'autre suivant toutes les varietés dont la matiere est capable. Qu'il ne faut pas chercher des causes finales [...] Ce sont en effect les sentimens de Spinoza, et il y a beaucoup de gens à qui des Cartes paroist de cette même opinion" (AA VI.4: 1385.04-1386.01).

9 Cf. Spinoza, 1677, I.xxxvi-Appendix: "Ut iam autem ostendam, naturam finem nullum sibi praefixum habere, et omnes causas finales nihil nisi humana esse figmenta, non opus est multis", assim como as proposições da primeira parte da Ethica às quais Spinoza reenvia no próprio Appendix. Para o comentário leibniziano a esta parte da Ethica, cf. Leibniz, 1678, AA VI.4: 1710.Anm.9.
} 
concepção spinozista fizesse deflagrar a contradição interna ao cartesianismo. De um lado, afirmar, como faz Spinoza - levando às últimas consequências o cartesianismo -, que Deus regula a natureza segundo fins imponderáveis, strictu senso, equivale a impossibilitar qualquer afirmação acerca da existência de fins, inclusive a cartesiana de Deus regular a natureza segundo fins imponderáveis. Ao assumir no sentido mais estreito - spinozanamente - a premissa cartesiana segundo a qual a deliberação e ação divinas são algo totalmente alheio a nós, Leibniz a retorque contra Descartes: qualquer nossa tentativa de compreensão da vontade de Deus seria tão vã que, a rigor, nada poderíamos dizer acerca dela, portanto, nem que Deus opera segundo bondade, ao contrário do que Descartes sustenta. De outro lado, afirmar, como faz Descartes, que Deus, por sua perfeição e bondade, prevê fins para a natureza significa que, embora os desígnios divinos permaneçam-nos desconhecidos, ao menos sabemos que a causalidade final, por escolha divina, é real e pertence às coisas, as quais, portanto, podem legitimamente ser explicadas a partir de seus fins, como afirma Leibniz. Ao assumir a premissa de Descartes segundo a qual Deus, perfeito e bom em sua deliberação e ação, estabelece fins para a natureza, Leibniz igualmente a retorque contra o próprio Descartes: a bondade e perfeição do querer e agir de Deus não se coadunam com sua pretensa indiferença sustentada por Descartes - para com a criação das leis físicas, pois os próprios conceitos de bondade e perfeição implicam analiticamente, segundo Leibniz, que Deus escolhe visando o melhor possível, isto é, orientando sua deliberação 


\section{Dossiê Leibniz, Dissertatio - Volume Suplementar 03 I UFPel [2016]}

e ação em vista de um fim. Então, não há razão para se excluir da física a explicação segundo causas finais, sendo que as leis da natureza, enquanto resultado da escolha divina, são constitutivamente moldadas conforme um princípio de determinação final.

Nesse sentido, é sugestivo que Molineux deixe também de enfatizar, negligenciando palavras explicitamente ressaltadas por Leibniz, que a pressuposição da causalidade final torna-se princípio heurístico fundamental e necessário para uma reconstrução completa dos fenômenos naturais. Não se trata de contrapor a posição leibniziana à cartesiana como se elas fossem excludentes uma com respeito à outra; nem, contudo, de justapor às explicações que aproveitam as causas eficientes as que aproveitem também as causas finais, como se só isso fosse suficiente para conciliá-las. Trata-se, antes, de apontar para a tese de Leibniz como apta a abarcar aquela do cartesianismo, conforme visto, a partir de uma explicação das determinações mecânicas que as contemple em sua relação a fins. Daí, enfim, é breve o passo dado por Molyneux, ao requalificar, abrandando-o, o princípio pelo qual é possível chegar às propriedades das coisas em sua verdadeira natureza, quando esta não se mostrar claramente para nós. A conotação da causalidade final acaba sendo transformada: o princípio referente a ela muda de "belíssimo", isto é, perfeito e sumamente harmônico, para "curioso", isto é, interessante, mas enquanto singular e inusitado, para não dizermos estranho ou bizarro. 
De resto, que Molyneux perca de vista o intuito originário e movimento dos raciocínios de Leibniz - provavelmente preocupado sobretudo em incorporar em seu tratado partes do ensaio leibniziano, para que, devidamente ponderadas, possam valorizar a própria Dioptrica nova - é confirmado pelo comentário que ele pospõe à sua tradução. Nesse comentário, Molyneux, independendo do texto de Leibniz, pode mostrar finalmente sua própria posição. Ao lado do comentário, à margem do texto, é indicado o título "Final causes highly deserve our notice", cujo sentido é explicado do modo seguinte:

Indeed I should think it an Attempt worth the Thought of some profound Philosopher, to give an Account of those admirable, orderly, and beautiful Appearances in Nature, whereof we can most plainly apprehend the Designs and Final Causes, but can hardly proceed to any farther Knowledge of them. (Thus for instance, suppose it were asked, What is the cause of refraction? Were it not much satisfactory to answer, That thereby the Ray may proceed the easiest way possible) This surely might be able to convince the most obstinate Opposers of Divinity: For certainly, if we can rely upon any Deduction or Consequence drawn out by the Mind of Man, we may assuredly rest satisfied in this, that so many Phenomena, stupendous and surprising for their designed Contrivance, could not proceed but from an Omnipotent and Designing Being (ibidem, p.195.18-31, itálico no original).

Segundo Molyneux, então, as causas finais merecem nossa alta consideração, desde que esteja claro que elas não servem para conhecermos os fenômenos naturais, mas apenas para nos darmos conta do fato de a natureza ser belamente ordenada. Em outros termos, apenas para satisfazermos nossa exigência subjetiva de pensarmos e relatarmos os eventos experimentados como pertencentes a um cosmo organizado (por Deus), sem que nisso resida alguma 


\section{Dossiê Leibniz, Dissertatio - Volume Suplementar 03 I UFPel [2016]}

possibilidade de aperfeiçoarmos nosso conhecimento deles. Nesse sentido, é inevitável que a resposta à questão sobre a causa da refração resulte insatisfatória, quando dada nos termos ironicamente lacônicos de Molyneux. Mas é exatamente este o ponto de desentendimento do grau de sofisticação da operação de Leibniz, o qual não pretende substituir as causas eficientes pelas finais, uma explicação mecanicista por uma finalística, como sugerido pela interpretação de Molyneux. Antes, Leibniz pretende à causalidade final seu estatuto epistemológico objetivo, exigido necessariamente, por sua função heurística, para a complementação e fundamentação da causalidade eficiente. As causas finais auxiliam as eficientes, na medida em que sustentam estas últimas, não limitando seu próprio papel apenas à manutenção de uma fé racional. Nesse sentido, podemos notar que já em 1682 Leibniz esboçara as linhas gerais de sua original concepção da relação entre os dois tipos de causalidade. Em questão está a possibilidade da investigação científica da natureza, constrangida indevidamente, segundo Leibniz, entre a posição spinozista, que reconduz todo fenômeno físico à necessidade da matéria ou do arbítrio incompreensível de Deus, e a posição cartesiana, que reduz todo fenômeno físico a princípios matemáticos. Em ambos os casos, como visto, não haveria lugar para a causalidade final na física. Ao contrário, Leibniz apela à própria prática da atividade científica, mostrando como é justamente a partir da pressuposição da existência objetiva de certa ordem natural, entendida em perspectiva finalista, que as relações causais mecânicas podem ser descobertas. Em outros termos, 
que o mundo seja determinado pela causalidade eficiente não constitui problema para Leibniz; o que se torna problemático é conseguirmos explicar o porquê da existência de uma específica causalidade eficiente entre as possíveis, se desconsiderarmos que as causas produzem seus efeitos conforme fins determinados (por Deus) para as coisas, isto é, se desconsiderarmos que as próprias relações causais mecânicas são fruto de um específico ato de escolha (de Deus) visando o melhor, a saber, a própria ordem natural. Nessa perspectiva, para Leibniz, se a explicação matemático-geométrica responde legitimamente à exigência de conhecermos como os mecanismos físicos funcionam segundo princípios matemáticos, é só a explicação que relaciona tais mecanismos à finalidade em vista da qual foram criados, que é capaz de responder à exigência de conhecermos por que eles assim funcionam, além de alimentar e nortear nossa busca por princípios matemáticos. É nesse sentido que afirmar que um raio de luz procede do modo mais simples de seu ponto de irradiação até seu ponto de iluminação, torna-se explicação física legítima e princípio heurístico válido.

Para Molyneux, no entanto, as causas finais não se relacionam propriamente com o conhecimento científico, mas só com as investigações de âmbito teológico, como ele confirma com toda evidência ao fim de seu comentário:

But if after all, they will arrive to such an height of Extravagance, as to say, We cannot rely on these Conclusions, as being all in the dark, and knowing nothing; let them look to the hazard of their own Principles, who endanger 


\section{Dossiê Leibniz, Dissertatio - Volume Suplementar 03 I UFPel [2016]}

their eternal Happiness on confidence of their own Arguments (ibidem, p.195.31-196.03, itálico no original).

Então, conforme Molyneux, não há outra opção entre, de um lado, uma concepção mecanicista - que logre preservar as causas finais, desde que estas sejam despojadas de qualquer significação científica e utilizadas apenas para piedosas reflexões sobre a necessidade de acreditarmos na magnificência divina perante a finitude de nossos conhecimentos - e, do lado oposto, o ceticismo absoluto de quem acredita que nada podemos concluir a partir das causas finais - o que a seus olhos seria uma extravagância que levaria ao ateísmo e ao perigo da perdição. Seja qual for a escolha, as causas finais encontram-se relegadas ao âmbito da mera especulação teológica, coisa que não se coaduna com o texto de Leibniz chamado em causa.

Se nossa leitura estiver correta, isto é, se a posição de Molyneux só prima facie se aproxima da de Leibniz, na verdade, distinguindo-se e afastando-se desta, devemos então nos interrogar sobre o motivo e a pertinência das alusões a Molyneux presentes na obra de Leibniz, as quais, como dito, além da referência ao problema de Molyneux, sempre reenviam à inclusão, na Dioptrica nova, da passagem sobre as causas finais do Unicum opticae, catoptricae e dioptricae principium. Pelo que sabemos, Leibniz refere-se a Molyneux, pela primeira vez, no ano 
seguinte à publicação da Dioptrica nova. Trata-se de uma das muitas cartas enviadas a Foucher ${ }^{10}$, em cujo incipit podemos ler:

Je suis bien aise que vous approuvés ce que j’y ay dit de la sagesse divine; j’ay trouvé que bien loin de negliger les causes finales en physique, on les peut employer utilement et faire des decouvertes. Et c'est par là que je rends raison dans les Actes de Lypsig des loix de la refraction et reflexion, ce qu'un Anglois nommé Molineux a fort approuvé dans un ouvrage publié depuis peu sur la dioptrique. Ce n'est pas qu'il ne vaudroit mieux d'en scavoir la cause efficiente, mais il est plus difficile de la penetrer (AA II.2: 710.25711.02, n. 225).

Leibniz confirma o que ele já afirmara em 1682, a saber, que as causas finais encontram sua específica utilidade na física, ao permitir avançarmos na descoberta das leis mecânicas dos fenômenos da natureza. O que está em questão, portanto, não é esquecer-se das causas eficientes, tampouco substituílas, mas auxiliá-las por meio das causas finais, pois estas nos resultam mais compreensíveis que aquelas. Nesse contexto, está inserida a menção a Molyneux, que, segundo Leibniz, "aprovou fortemente" o caminho pelo qual o Unicum opticae, catoptricae e dioptricae principium chegou à demonstração das leis de refração e reflexão. Não sabemos se Leibniz está aqui se referindo rapidamente à adaptação geral de seu texto feita por Molyneux na segunda das duas passagens traduzidas na Dioptrica Nova. Só podemos notar que Leibniz continua relacionando a legítima função heurística das causas finais na física à sabedoria divina, isto é, à perfeição e bondade que orientam suas escolhas. De todo modo,

10 Sobre a relação intelectual entre Leibniz e Foucher, cf. POPKIN, 1966, p. 228-248, e, em particular, Brown, 2004, p. 74-96. 


\section{Dossiê Leibniz, Dissertatio - Volume Suplementar 03 I UFPel [2016]}

porém, não há indício de uma distinção, por parte de Leibniz, entre as duas passagens, mas, ao contrário, os dois momentos apresentam-se tão incindíveis nestas rápidas linhas a Foucher, que poderíamos supor que aqui Leibniz esteja recordando diretamente seu próprio ensaio de 1682, e não o tratado de Molyneux de 1692.

A primeira referência pública, embora não explícita, a Molyneux encontra-se no Tentamen Anagogicum, tratado de 1696, em que Leibniz deriva todos os fenômenos óticos da assunção da causalidade final. Na verdade, Leibniz está retomando teses já formuladas uma década atrás, no Discours de Métaphysique, no qual ele chega à conclusão de que os fenômenos naturais podem ser demonstrados através tanto das causas eficientes quanto das causas finais ${ }^{11}$. Tal concepção é proposta a partir da observação da perfeição da estrutura dos seres animados, a qual revela que as relações causais sempre ocorrem seguindo a via mais fácil e breve, isto é, realizando-se conforme o princípio de economia da natureza, que prevê os máximos efeitos mediante os mínimos recursos (cf. GP VII 270.01-273.20). É nesse contexto que Leibniz reafirma também a dupla perspectiva a partir da qual é possível conhecermos a ordem natural.

C'est pour cela que j'ay coustume de dire qu'il y a, pour parler ainsi, deux Regnes dans la nature corporelle même qui se penetrent sans se confondre et sans s'empecher: le regne de la puissance, suivant lequel tout se peut

\footnotetext{
${ }^{11}$ Muito interessante a relação explicitamente estabelecida por Leibniz com seu escrito de 1682: "Je trouve même que plusieurs effects de la nature se peuvent demonstrer doublement, sçavoir par la consideration de la cause efficiente; et encor à part par la consideration de la cause finale, en se servant par exemple du decret de Dieu de produire tousjours son effect par les voyes les plus aisées, et les plus determinées, comme j'ay fait voir ailleurs en rendant raison des regles de la catoptrique et de la dioptrique, et en diray d'avantage tantost" (AA VI.04: 1563.27-1564.03).
} 
expliquer mecaniquement par les causes efficientes, lorsque nous en penetrons assez l'interieur; et aussi le Regne de la sagesse, suivant lequel tout se peut expliquer architectoniquement, pour ainsi dire, par les causes finales, lorsque nous en connoissons assez les usages (GP VII 273.03-09).

Trata-se da conhecida distinção entre o reino das causas eficientes e o das causas finais, o primeiro ligado à potência ínsita nos corpos, conforme sua constituição físico-mecânica, o segundo à estrutura arquitetônica através da qual os fenômenos individuais se relacionam em um todo orgânico e sistemático chamado natureza. A existência de dois níveis explicativos da natureza garante, em primeiro lugar, a autonomia interna de ambos os tipos de explicação, os quais são capazes de dar conta, cada um por si só, das coisas de ordem natural. A esses dois níveis explicativos correspondem duas ciências distintas, a metafísica e a física, cada uma referente a um olhar específico sobre o mesmo objeto, os fenômenos naturais. Ao mesmo tempo, a coexistência desses dois níveis e dessas duas ciências não impede uma sua interação e hierarquização, em vista de um conhecimento perfeito da natureza. De um lado, então, Leibniz retoma a possibilidade de tanto a física quanto a metafísica conseguirem explicações coerentes e sensatas dos fenômenos naturais ao aproveitarem, respectivamente, cada uma no seu domínio, a causalidade eficiente e a final; de outro, todavia, afirma também a necessidade de a física aprimorar suas explicações mediante o auxílio que a metafísica lhe oferece ao contemplar a ordem natural em sua organicidade e sistematicidade, conforme a escolha de Deus de criá-la em vista do melhor. Nesse sentido, a metafísica tornar-se-á 


\section{Dossiê Leibniz, Dissertatio - Volume Suplementar 03 U UFPel [2016]}

ciência de fundamentação da física, sem que isso interfira na suficiência interna desta última ${ }^{12}$. Tais considerações são testadas através de sua aplicação aos problemas físicos - por exemplo, os da ótica - em uma espécie de movimento circular, que comprova sua própria validade epistêmica. Se, como afirmado por Leibniz desde 1682, a pressuposição da causalidade final serve de contribuição para trazer à tona princípios físicos ainda não manifestos, as explicações nos termos da causalidade eficiente, por sua vez, servem para verificar e confirmar a exatidão das explicações que aproveitam as causas finais ${ }^{13}$. É nesse sentido que Leibniz usa seu método, na passagem do Tentamen Anagogicum em que se encontra a menção a Molyneux.

De plus nos meditations nous fournissent quelques fois des considerations, qui font voir l'usage des Finales, non seulement pour augmenter l'admiration de l'Auteur supreme, mais encor pour faire des decouvertes dans son ouvrage. Et je le monstray un jour par un echantillon, lors que je proposay le principe general d'optique, que le rayon se conduit d'un point à l'autre par la voye qui se trouve la plus aisée, à l'egard des superficies planes, qui doivent servir de regle aux autres. Car il faut considerer que si on pretendoit l'employer comme une cause efficiente, et comme si tous les rayons possibles balancés entre eux le plus aisé l'emportoit, il faudroit considerer toute la surface telle qu'elle est, sans considerer le plan qui la touche, et alors la chose ne reussiroit pas toujours comme on dira tantost. Mais bien loin de dissimuler que ce principe a quelque chose de la cause finale, comme on avoit objecté autres fois à Monsieur Fermat, qui l'avoit employé pour la Dioptrique, je l'en trouvois plus beau et plus considerable pour un usage plus sublime que celuy du mecanisme. Et un habile auteur ${ }^{14}$ qui publia un ouvrage d'Optique en Angleterre témoigna de m'en sçavoir bon gré (GP VII 273.21-274.02).

12 Sobre o assunto cf., por exemplo, Mendonça (2012), p. 471-474.

${ }^{13}$ Acerca do caráter autorreferencial do método leibniziano na explicação científica, cf. Parkinson (1965), p. 117-123, e Gale (1982), p. 8-16.

${ }^{14}$ Como assinalado por Gerhardt, no manuscrito, Leibniz anotou o nome de Molyneux à margem da folha. 
A pressuposição das causas finais torna-se evidente, na exposição de Leibniz, exatamente em face da demonstração de que o experimento não seria tão exitoso, "se pretendermos utilizar como causa eficiente" um princípio que ao contrário remete à causalidade final. Ao enfatizar a utilidade e até a necessidade da causalidade final em física, Leibniz não está propriamente excluindo a possibilidade de uma explicação respaldada apenas na mera causalidade eficiente. Ele só aponta para o fato de que é exatamente em vista de uma sistematização definitiva, isto é, a melhor possível, seja no modo de sua realização como nos resultados, que explicar um fenômeno natural - por exemplo, o da refração da luz - nos termos da causalidade final é útil e até necessário em física. Poder-se-ia muito bem explicar o mesmo fenômeno apenas nos termos da causalidade mecânica (considerando o raio de luz que resultaria como uma espécie de raio padrão após ponderarmos todos os raios possíveis, dada a superfície em questão), mas, neste último caso, atingir-se-ia apenas um resultado que, mesmo que válido, porquanto correto, seria provisório, pois parcial (no exemplo, limitado aos raios de luz refratados por uma superfície especificamente dada). Nem serve dissimular a causalidade final, disfarçando-a de causa eficiente: conforme a perspectiva de Leibniz, afirmar que um raio de luz procede pela via mais simples possível, não pode ser stricto sensu demonstrado através de cálculos matemático-geométricos, os quais, por se referirem sempre a fenômenos particulares, só podem mostrar a validade de princípios de outro 


\section{Dossiê Leibniz, Dissertatio - Volume Suplementar 03 UFPel [2016]}

nível, que os estimulam, auxiliam e norteiam. Quanto a Molyneux, Leibniz registra muito simples e rapidamente que o primeiro inseriu de bom grado as causas finais em seu tratado de ótica. Mas, assim como ocorre na carta a Foucher, também aqui nada é dito a propósito da reelaboração que Molyneux faz da proposta leibniziana.

Muito semelhante nesse aspecto à citação presente na carta a Foucher é também a primeira referência pública e explícita a Molyneux, na Reponse aux reflexions qui se trouvent dans le 23 Journal des Sçavans de cette année touchant les consequences de quelques endroits de la philosophie de des Cartes, de 1697. Leibniz está respondendo ao cartesiano Pierre-Silvain Régis ${ }^{15}$, a propósito das Reflexions sur une lettre de Monsieur Leibnits écrite à Monsieur l'Abbé Nicaise ${ }^{16}$, dans laquelle il pretend faire voir que les principes de la Philosophie de Monsieur Descartes renferment des consequences contraires à la Religion et à la pieté, publicadas poucos meses antes. Régis questiona as acusações endereçadas por Leibniz a Descartes, em particular a de que Descartes teria banido da filosofia a busca por causas finais e, então, pela sabedoria divina na ordem natural, bem como a de Descartes ter sustentado que a matéria assume qualquer forma possível até ela chegar necessariamente por si mesma à sua forma definitiva, seguindo-se disso que não há nem escolha nem providência.

\footnotetext{
${ }^{15}$ As Reflexions são publicadas anonimamente no Journal des Sçavans. Para a identificação do autor, cf. Gerhardt (1880), GP IV 270.12-28, útil também para a contextualização da querela anticartesiana de Leibniz. Para uma apresentação panorâmica do debate sobre o cartesianismo, cf. Brunschvicg (1939), capítulo VI. Période Leibnizienne.

${ }^{16}$ Cf. AA II.3: 273.01-16, n. 100, parcialmente publicado por Régis no Journal des Sçavans.
} 
A tentativa feita por Régis de refutação da primeira dessas acusações a que nos interessa ${ }^{17}$ - consiste em afirmar que, "si c'est de la Philosophie morale [que Mr. Descartes bannit les causes finales], il [Leibniz] a tort: car tout le bien et tout le mal de nos actions libres depend de leur fin. Mais si c'est de la Philosophie naturelle, il a raison: car en Physique on ne demande pas pourquoi les choses sont, mais comment elles se font" (RÉGIS, 1697, p. 241.24-28). Para Leibniz a resposta de Régis é "surpreendente", pois “il ne s'agit pas de nos actions libres dont il est bien vray qu'on traite dans la morale, mais des Actions libres de Dieu et de sa sagesse, qui paroist dans l'ordre des choses que M. des Cartes ne devoit point negliger"' (GP IV 339.06-09). A procura por causas finais deve ser referida à nossa investigação do mundo entendido como um todo sistemático, estando em questão, antes de tudo, a ação divina que "se manifesta na ordem das coisas", ou seja, na ordem de todos os fenômenos, inclusive daqueles - e não limitadamente àqueles - que, do ponto de vista de um conhecimento finito, são abordados como morais. É por aí que Leibniz responde diretamente a Régis:

Mais (dit on) en Physique on ne demande point pourquoy les choses sont,
mais comment elles sont. Je reponds qu'on y demande l'un et l'autre.
Souvent la fin et l'usage fait deviner le comment, parce qu'en connoissant la
fin, on peut mieux juger des moyens. Outre que pour expliquer une
Machine, on ne sçauroit mieux faire, que de proposer son but, et de

${ }^{17}$ A segunda acusação simplesmente é negada, pois "Mr. Descartes n'a jamais enseigné que la matiere reçoive successivement toutes les formes possibles: il a dit seulement qu'elle les peut recevoir, comme il paroît par l'article 203. et 204. de la quatrieme partie des principes" (RÉGIS, 1697, p. 241.06-10). Com igual simplicidade Leibniz sugerirá a Régis ler melhor Descartes: "L’Auteur des Reflexions me demande l'endroit, où M. des Cartes dit que la matiere reçoit successivement toutes les formes dont elle est capable. II l'a cherché artic. 203 et 204 de la quatrieme partie de ses principes. Mais il se trouve dans l'article 47 de la $3^{\text {me }}$ partie" (GP IV 340.18-21). 


\section{Dossiê Leibniz, Dissertatio - Volume Suplementar 03 UFPel [2016]}

monstrer comment toutes les pieces y servent. Cela peut même estre utile à trouver l'origine de l'intention. Je voudrois qu'on se servit de cette Methode encor dans la Medicine (GP IV 339.28-35).

Leibniz reafirma a utilidade das causas finais para mostrar seja como se dão determinados mecanismos físicos, seja porquê. É retomado exatamente aquele paralelismo entre causas eficientes-causas finais e meios-fins, que já notamos ressaltados pela tradução de Molyneux, agora todavia relacionado não à física, mas à medicina, a qual assume aqui papel central na argumentação, assim como a biologia no Tentamen Anagogicum e no Discours de Métaphysique ${ }^{18}$. E não em vão Leibniz se refere à medicina, pois, como dito, é o estudo dos corpos animados que nos faz descobrir, mais que todas as outras ciências, os dois reinos causais aptos ao conhecimento dos corpos em geral, considerados todos como máquinas determinadas em vista de um fim em analogia com os corpos dos animais. A medicina parece prestar-se como momento exemplar para que causas eficientes e causas finais encontrem seu conúbio mais harmônico.

Le corps de l'animal est une Machine en même temps Hydraulique, pneumatique et pyrobolique, dont le but est d'entretenir un certain mouvement; et en monstrant ce qui sert à ce but et ce qui nuit, on feroit connoistre tant la Physiologie que la Therapeutique. Ainsi on voit que les causes finales servent en Physique, non seulement pour admirer la sagesse de Dieu, ce qui est le principal, mais encor pour connoistre les choses et pour les manier (GP IV 339.35-340.05).

${ }^{18}$ Cf., respectivamente, GP VII 273.09-20 e AA VI.4: 1561.03-08. 
O corpo dos seres animados enquanto máquina voltada ao movimento, torna-se paradigma para Leibniz exemplificar a validade das causas finais. Tratando-se aqui de medicina, tudo deixa imaginar que seja nosso corpo o tema central em questão. E é exatamente através de nosso corpo que se torna imediatamente perceptível - pois experimentada diretamente "na nossa pele" a necessidade de considerarmo-nos não apenas seres sujeitos às regras mecânicas, mas também seres capazes de outro tipo de determinação causal. Além de representar um válido princípio heurístico para a compreensão das explicações mecânicas do corpo, a causalidade final permite também, por exemplo, manejarmos tal máquina a fins terapêuticos. O que está em jogo não é apenas o bom funcionamento (mecânico) do organismo, conforme sua constituição física, mas também a consciência de que nosso organismo existe em vista de sua saúde. Contudo, que a medicina ofereça uma visão mais clara da questão não diminui a validade da tese de 1682, aliás, a corrobora. De resto: por que o que vale para corpos específicos e para uma ciência em particular não deveria valer para a natureza em geral? Voltando para a física, Leibniz repropõe mais uma vez a referência ao Unicum opticae, catoptricae e dioptricae principium e à

\section{Dioptrica nova.}

J'ay monstré ailleurs, que tandis qu'on peut encor disputer de la cause efficiente de la lumiere, que M. des Cartes n'a pas assés bien expliquée, comme les plus intelligens avouent maintenant, la cause finale suffit pour deviner les loix qu'elle suit: car pourveu qu'on se figure, que la nature a eu pour but de conduire les rayons d'un point donné à un autre point donné par le chemin le plus facile, on trouve admirablement bien toutes ces loix, en employant seulement quelques lignes d'Analyse, comme j'ay fait dans les Actes de Leipzig. Mons. Molineux m'en a sçû bon gré dans sa Dioptrique, 


\section{Dossiê Leibniz, Dissertatio - Volume Suplementar 03 I UFPel [2016]}

et il a fort approuvé la remarque que j'avois faite à cette occasion du bel usage des causes finales, qui nous eleve à la consideration de la Souveraine Sagesse, en nous faisant connoistre en même temps les loix de la nature qui en sont la suite (GP IV 340.05-17).

Desta vez, é evidente a referência à tradução da segunda passagem do Unicum opticae, catoptricae e dioptricae principium, mas continua despercebida a posição que Molyneux assume em seu comentário a tal passagem. Por outro lado, nesse contexto de explícita polêmica contra um notório defensor ortodoxo $^{19}$ do cartesianismo, nos parece razoável supor que a citação de Molyneux seja utilizada por Leibniz pro domo sua, enfatizando a presença, na Dioptrica nova, de um equilíbrio entre causas eficientes e causas finais, que, como visto, logo desaparece quando Molyneux expressa suas críticas. O redimensionamento do papel das causas finais feito por Molyneux nos parece silenciado por Leibniz, em vista de outro objetivo, mínimo, a saber, mostrar como até um intelectual notoriamente posicionado a favor de uma visão mecanicista da física, consegue - contra Descartes - reservar espaço para as causas finais. Fica claro, no entanto, que os pressupostos de Molyneux e Leibniz continuam opostos, como mostrado anteriormente: de um lado, a aceitação da causalidade final exclusivamente no âmbito de uma moral religiosa; do outro, o reiterado reconhecimento ao finalismo de seu valor de aprimoramento da física.

\footnotetext{
${ }^{19}$ Régis é autor do Cours entier de philosophie, ou système général selon les principes de M. Descartes, e da Reponse au Livre qui a pour titre: Censura Philosophiae Cartesianae, servant d'eclaircissement à toutes les parties de la philosophie et sur tout à la Metaphysique.
} 
Leibniz confirma o dúplice movimento da causalidade final, capaz de contribuir para explicar melhor as leis físicas, sem impossibilitar que haja uma explicação correta nos meros termos das causas mecânicas. Nesse sentido, Descartes, ao reduzir o fenômeno da refração à mera causalidade eficiente, conseguiu explicálo, mas "não tão bem" como poderia, se tivesse aceitado também uma abordagem finalista.

Esse mesmo debate sobre o cartesianismo aflora novamente em outro escrito de Leibniz em que, novamente, é citado Molyneux, a saber, no De ipsa natura sive de vi insita actionibusque Creaturarum, pro Dynamicis suis confirmandis illustrandisque, de 1698, em que Leibniz responde a Johann Christoph Sturm ${ }^{20}$. O dualismo cartesiano aceito por Sturm quanto à distinção entre mente e corpo, e, então, entre seres dotados de livre arbítrio e autômatos, permite que Leibniz expresse, a partir de sua própria concepção da substância, a posição sustentada desde 1682. Pois uma descrição meramente mecanicista dos fenômenos naturais não conseguiria explicar, por exemplo, como ocorrem nossas percepções, quando consideradas como informações que recebemos acerca da natureza, por sua vez julgada como um todo que faça sentido enquanto tal ${ }^{21}$. Embora, em

\footnotetext{
20 Para a reconstrução histórico-filosófica do debate entre Leibniz e Sturm, cf. Woolhouse (1988), p. 165183, e Palaia (1990), 157-172.

21 Uma quinzena de anos depois, na Monadologie, Leibniz escreverá: "17. On est obligé d'ailleurs de confesser, que la Perception et ce qui en depend, est inexplicable par des raisons mecaniques, c'est à dire par les figures et par les mouvemens" (GP VI 609.20-22).
} 


\title{
Dossiê Leibniz, Dissertatio - Volume Suplementar 03 I UFPel [2016]
}

termos gerais, Leibniz e Sturm concordem ambos com Boyle ${ }^{22}$, ao afirmarem que a natureza é apenas o mecanismo de corpos, no entanto, para Leibniz,

\begin{abstract}
distinguenda erant in ipso mechanismo principia a derivatis ut in explicando horologio non satis est, si mechanica ratione impelli dicas, nisi distinguas, pondere an elastro concitetur. Et a me aliquoties jam est proditum [...] originem ipsius Mechanismi non ex solo materiali principio mathematicisque rationibus, sed altiore quodam et, ut sic dicam, Metaphysico fonte fluxisse (GP IV 505.26-34).
\end{abstract}

Só distinguindo entre "elementos principiais e derivados", ou, melhor, entre princípios de primeiro e segundo nível, é possível aceitarmos como satisfatórias explicações que se inserem cada qual em sua ordem de princípios ${ }^{23}$. Um princípio de ordem metafísico torna-se necessário, para Leibniz, se quisermos explicar clara e satisfatoriamente as causas que determinam mecanicamente todos os fenômenos naturais, e também seu motivo originário. Nesse sentido, retorna, afirmada de modo cristalino, a tese de 1682. Não se trata de excluir as causas eficientes, nem de juntar-lhes as finais, mas, sim, de enquadrar estas naquelas, pois, caso contrário, as causas eficientes não fariam pleno sentido, ou melhor, não seriam perfeitamente significativas. Evidentemente, o pressuposto de Leibniz reside na recusa de qualquer brecha de irracionalidade na explicação da natureza: uma explicação meramente mecanicista dos específicos fenômenos naturais não passaria de uma verdade

22 Sobre a posição de Leibniz perante os elementos cartesianos em Boyle, cf., por exemplo, Brown (2007), p. 90-92.

${ }_{23}$ Sobre o conceito de princípio no De ipsa natura e sua formação, cf. Wilson (1987), p. 154-162. 
parcial, internamente correta e coerente, mas incapaz de oferecer uma compreensão plena da ordem natural, como algo escolhido em vista do melhor, isto é, perfeitamente planejado. É neste contexto que comparece a referência a Molyneux.

Puto enim determinatis sapientiae atque ordinis rationibus, ad eas quae in natura observantur ferendas leges venisse Deum: et vel hinc apparere, quod a me aliquando Opticae Legis occasione est admonitum et $\mathrm{Cl}$. Molineuxio in Dioptricis postea valde se probavit, Finalem causam non tantum prodesse ad virtutem et pietatem in Ethica et Theologia naturali, sed etiam in ipsa Physica ad inveniendum et detegendum abditas veritates (GP IV 506.1622).

Todavia, Leibniz ainda não percebe a distância entre sua posição e a de Molyneux. É provável que, ainda, a necessidade de defesa de seu sistema junto com o ataque de sempre ao cartesianismo, em suas formas tanto patentes quanto latentes, impeçam que Leibniz se depare com a função minimizada que Molyneux atribui às causas finais. $\mathrm{O}$ mesmo desentendimento repetir-se-á poucos anos depois, em uma carta a Wolff, na qual Leibniz continuará insistindo sobre a aceitação de seu ponto de vista por parte de Molyneux.

Finium contemplatio etiam ad inveniendum facit: hinc in specimine aliquo Actorum Lipsiensium legem Opticae, Catoptricae et Dioptricae communem ex fine deduxi, dum efficiens controversa est. Nam saepe nos efficientes latent, effectus patent ex quibus finis agnoscitur. Hoc consilium meum in Optica Anglice edita valde laudavit Molineusius. Anatomiam quoque animalis finium methodo tractandam putem, ex. gr. considerando corpus humanum ut machinam propagandae sapientiae causa excogitatam, inde tum cognitionis organa, tum conservatio animalis et speciei (LW 42.02-10, n. 7). 


\section{Dossiê Leibniz, Dissertatio - Volume Suplementar 03 UFPel [2016]}

Além de reiterar as avaliações anteriores, Leibniz retoma também a referência à medicina anatômica e o exemplo do corpo dos seres animados, agora confirmando explicitamente o interesse pelo corpo humano, o qual mostra a íntima racionalidade da natureza. A posição de Leibniz é, afinal, a de um metafísico para o qual a existência de uma ordem não completamente desvelada torna-se fundamento e princípio de qualquer explicação inteligível da ordem da natureza observável. Nesse sentido, a explicação finalista dos fenômenos naturais carrega, antes de um significado metodológico, um peso ontológico. Parece-nos que nesses termos poderia ser lida a última conotação com que Leibniz apresenta, nos Nouveaux Essais, o debate sobre as causas eficientes e finais, ao envolver nele Molyneux.

PH. Au moins il semble, que tel usage qu'on voudra faire des Maximes dans les propositions verbales elles ne nous sauroient donner la moindre connoissance sur les substances, qui existent hors de nous.

TH. Je suis tout d'un autre sentiment. Par exemple cette Maxime, que la nature agit par les plus courtes voyes, ou du moins par les plus determinées, suffit seule pour rendre raison presque de toute l'Optique, Catoptrique et Dioptrique, c'est à dire de ce qui se passe hors de nous dans les actions de la lumiere, comme je l'ay monstré autrefois et M. Molineux l'a fort approuvé dans sa Dioptrique, qui est un très bon livre (GP V 404.13-21).

As máximas ou axiomas - como especificado no título do capítulo nada são senão aquelas proposições que se referem a princípios metafísicos, ou seja, a princípios de primeiro nível, portanto, incondicionados e absolutos, e capazes de determinar ulteriores princípios de nível inferior. Embora as causas finais não sejam mencionadas, é evidente que Leibniz esteja falando delas, seja 
pela transformação do único princípio da ótica inteira, a "hipótese primária” de 1682, em máxima, seja pela habitual referência a Molyneux. Mais uma vez, Leibniz perde a ocasião de distinguir qual é sua própria posição, em última instância, derivada de sua imprescindível relação ontológica entre metafísica e física. Afinal, a pressuposição de uma natureza governada arquitetonicamente conforme os fins que Deus decretou em sua sabedoria, torna-se fundamental para todas as explicações nos termos das causas finais, isto é, para a justificação do uso da causalidade final como instrumento heurístico na procura por princípios e leis que se servem da causalidade eficiente, mecânica e matemática. O próprio Leibniz, como visto, insiste nesse ponto, ao chamar em causa a investigação da biologia e da medicina. Todavia - como Molyneux percebe talvez Leibniz não ofereça uma explicação de como seja possível conciliar mecanismo e finalismo. A não ser que - como Leibniz deixa a entender e como rapidamente apontamos neste trabalho - a única explicação possível seja a oferecida, nos termos da causalidade final, pelo mesmo princípio de perfeição que a natureza exibe in infinitum em todas as suas partes, cada uma em sua própria ordem de grandeza, até incluir a tensão sistemática própria de nossa razão.

\section{Obras de Leibniz}

LEIBNIZ, Gottfried Wilhelm (1682). "Unicum opticae, catoptricae e dioptricae principium". Acta eruditorum, vol. I, 1682, p. 185-190. 
Sämtliche Schriften und Briefe. Hrsg. von Akademie der

Wissenschaften. Darmstadt u. Berlin: Akademie-Verlag/De Gruyter, 1923ss.:

- (1678). "Aus und zu Spinozas Opera posthuma. Randbemerkungen, Unterstreichungen und Exzerpte aus der Ethica". AA VI.4. Philosophischer Schriften 1677-Juni 1690. Teil B. 1999, p. 1705-1751.

- $\quad(1678 / 1680)$. "Sentiments de Socrate opposés aux nouveaux Stoiciens et Epicureens”. AA VI.4. Philosophischer Schriften 1677-Juni 1690. Teil B. 1999, p. $1384-1388$.

- (1679). "Definitiones: Aliquid, Nihil". AA VI.4. Philosophischer Schriften 1677-Juni 1690. Teil A. 1999, p. 306-310.

- (1686). "Discours de Métaphysique". AA VI.4. Pbilosophischer Schriften $1677-$ Juni 1690. Teil B. 1999, p. 1529-1588.

- (1693). "Lettre n. 225, à Foucher, fin de Juin de 1693”. AA II.2. Philosophischer Briefwechsel 1686-1694. 2009, p. 708-711.

- (1697a). "Lettre n. 100, à Nicaise, 20 Février 1697”. AA II.3: Philosophischer Briefwechsel 1695-1700. 2013, p. 271-276.

Die philosophischen Schriften von Gottried Wilhelm Leibniz. Hrsg. von

Gerhardt, Carl Immanuel. Berlin: Weidmann, 1875-1890: 
- (1696). "Tentamen Anagogicum. Essay anagogique dans la recherche des causes”. GP VII. Philosophische Abhandlungen. Ergänzungen. 1890, p. 270-279.

- (1697b). "Reponse aux reflexions qui se trouvent dans le 23 Journal des Sçavans de cette année touchant les consequences de quelques endroits de la philosophie de des Cartes". GP IV. Leibni₹gegen Descartes und den Cartesianismus 1677-1702. 1880, p. 336-342.

- (1698). "De ipsa natura sive de vi insita actionibusque Creaturarum, pro Dynamicis suis confirmandis illustrandisque". GP IV. Philosophische Abhandlungen 1684-1703. 1880, p. 504-516.

- (1704). "Nouveaux Essais sur l'Entendement". GP V. Leibniz und Locke. 1882, p. 39-509.

- (1714). "Monadologie". GP VI. Philosophische Abhandlungen 1702-1716. 1885, p. 607-623.

(1705). "Brief n. VIII, 9 November 1705". [LW] Der Briefwechsel zwischen Leibniz und Christian Wolff. Hrsg. von Carl Immanuel Gerhardt. Halle: Schmidt, 1860, p. 43-46. 


\section{BIBLIOGRAFIA}

BERKELEY, George (1709). An Essay towards a new Theory of Vision. Ed. by David Wilkins. Dublin: Trinity College, 2002.

BROWN, Stuart (2004). “The Leibniz-Foucher alliance and its philosophical bases”. In: LODGE, Paul. Leibniz and His Correspondents. New York: Cambridge University Press, 2004, p. 74-96.

(2007). "Leibniz and Robert Boyle. Reason and faith: Rationalism and voluntarism". In: PHEMISTER, Pauline; BROWN, Stuart (eds.). Leibniz and the English-Speaking World. Dordrecht: Springer, 2007, p. 83-93.

BRUNSCHVICG, Léon (1939). La raison et la religion. Paris: Alcan, 1964 (2a ed.).

BUCHDAHL, Gerd (1969). Metaphysics and the Philosophy of Science. The Classical Origins: Descartes to Kant. Oxford: Basil Blackwell, 1969.

DASCAL, Marcelo; FIRT, Erez (2010). “Leibniz's conciliatory approaches in scientific controversies". In: DASCAL, Marcelo (ed.). The Practice of Reason. Leibniz and his Controversies. Amsterdam/Philadelphia: John Benjamins Publishing Company, 2010, p. 137-167.

DESCARTES, René. Oeuvres. Publ. pour Charles Adam et Paul Tannery. Paris: Léopold Cerf, 1897-1913: 
- (1641). "Méditations métaphysiques". AT IX Méditations et Principes. $1904,1^{\mathrm{e}}$ partie.

- (1644). "Les Principes de la philosophie". AT IX Méditations et Principes. 1904, 2e partie.

GALE, Geroge (1982). "Theory and Practice in Science: Leibniz, Conservation Principles, and the Gap between Theory and Experiment". Studia Leibnitiana. Supplementa. v. 21, n. 4, 1982, p. 8-16.

GERHARDT, Carl Immanuel (1880). "Einleitung”. In: GP IV. Leibniz gegen Descartes und den Cartesianismus 1677-1702. 1880, p. 265-273.

LIEVERS, Menno (1992). "The Molyneux Problem". Journal of the History of Philosophy, v. 30, n. 3, 1992, p. 399-416.

LOCKE, John (1694). An Essay concerning Human Understanding. London: T. Tegg and Son, 1836.

MENDONÇA, Marta (2012). "O “reino das causas eficientes” e o "reino das causas finais" em Leibniz". Rev. Filosofía Univ. Costa Rica, LI (129-131), 2012, p. 469-477.

MOLYNEUX, William (1688). "Letter n. 1064, to John Locke, 07 July 1688”. In: DE BEER, Esmond Samuel. The Correspondence of John Locke, vol. 3. Oxford: Clarendon Press, 1978, p. 482-483. 
(1692). Dioptrica nova. London: Benj. Tooke, 1709.

(1693). "Letter n. 1609, to John Locke, 02 March 1693”. In: DE

BEER, Esmond Samuel. The Correspondence of John Locke, vol. 4. Oxford: Clarendon Press, 1979, p. 647-652.

PALAIA, Roberto (1990). "Naturbegriff und Kraftbegriff im Briefwech sel zwisch en Leibniz und Sturm". In: MARCHLEWITZ, Ingrid; HEINEKAMP, Albert (hrsg.). Leibniz' Auseinandersetzung mit Vorgängern und Zeitgenossen (Studia Leibnitiana. Supplementa 27). Wiesbaden: Franz Steiner, 1990, p. 157-172.

PARKINSON, George Henry Radcliffe (1965). Logic and Reality in Leibniz's Metaphysics. Oxford: Oxford University Press, 1969 (2a ed.).

POPKIN, Richard Henry (1966). "Leibniz and the French skeptics". Revue Internationale de Philosophie. v. 76-77, 1966, p. 228-248.

RÉGIS, Pierre-Silvain (1697), "Reflexions sur une lettre de Monsieur Leibnits écrite à Monsieur l'Abbé Nicaise, dans laquelle il pretend faire voir que les principes de la Philosophie de Monsieur Descartes renferment des consequences contraires à la Religion et à la pieté”. Le Journal des Sçavans, 17 Juin 1697, p. 240-247. Também in: GP IV. Leibnizgegen Descartes und den Cartesianismus 1677-1702. 1880, p. 333-336. 
SPINOZA, Baruch (1677). "Ethica ordine geometrico demonstrata". In: Opera, vol. 2. Hrsg. von Carl Gebhardt. Heidelberg: Carl Winter, 1925, p. 43-308.

SYNGE, Edward (1695). "Letter n. 1984, to Francis Quayle, 6 September 1695”. In: DE BEER, Esmond Samuel. The Correspondence of John Locke, vol. 5. Oxford: University Press, 1974, p. 494-496.

WILSON, Catherine (1987). "De Ipsa Natura. Sources of Leibniz's Doctrines of Force, Activity and Natural Law”. Studia Leibnitiana. v. 19, n. 2, p. 145-72.

WOOLHOUSE, Roger Stuart (1988). "Leibniz and Occasionalism". In: WOOLHOUSE, Roger Stuart (ed.). Metaphysics and Pbilosopby of Science in the Seventeenth and Eighteenth Centuries. Essays in honour of Gerd Buchdabl. Dordrecht/Boston/London: Kluwer Academic Publishers, 1988, p. 165-183. 